\title{
Acides gras oméga 3 : aspects métaboliques
}

Oléagineux, Corps Gras, Lipides. Volume 11, Numéro 1, 29, JANVIER/FÉVRIER 2004, Dossier

Auteur(s) : Bernard Guy-Grand, Président du GLN

\section{ARTICLE}

Le Groupe Lipides Nutrition, GLN pour les intimes, est constitué d'un groupe, en effet, de chercheurs et de médecins que réunit un intérêt commun pour les effets nutritionnels des lipides, l'une des grandes thématiques du moment, riche de débats passionnés, voire passionnels.

Ce groupe, animé par un conseil d'administration qui ressemble davantage, par sa composition et ses actions, à un conseil scientifique qui a une assemblée "d'administrateurs ", s'est donné deux objectifs.

Le premier est de contribuer à aider la recherche en subventionnant, dans la faible mesure de ses possibilités financières, quelques projets - entre trois et cinq par an - soumis par des équipes ou de jeunes chercheurs en réponse à un appel d'offre public. Soumis à l'évaluation rigoureuse du conseil, ces projets, dans lesquels les mots-clefs doivent bien entendu être Nutrition et Lipides reçoivent en général des financements complémentaires pour deux ans avec évaluation intermédiaire.

Le second est d'organiser chaque année une réunion scientifique à thème dont le succès va croissant. Après " Acides gras : transport, régulation génique et implication dans l'étiologie des maladies de pléthores " en 2002, quelques-uns des effets physiologiques et physiopathologiques des acides gras oméga 3 ont été abordés en 2003, devant un large public. Le lecteur trouvera ci-après, la restitution des différentes conférences de cette journée.

Pour 2004 - le 4 novembre - ce sera la nature et le rôle des CLA qui seront abordés. Le GLN contribue ainsi à la diffusion d'une information scientifique rigoureuse et libre.

Le vœu de son président est de voir augmenter le budget du GLN au service d'une efficacité et d'une notoriété accrue. 